The original publication is available at www.springerlink.com DOI: $10.1007 / \mathrm{s} 11120-011-9670-0$

http://www.springerlink.com/content/05823m1772u3h003/ 


\section{Editorial Manager(tm) for Photosynthesis Research}

Manuscript Draft

Manuscript Number:

Title: Self-assembly and energy transfer in artificial light-harvesting complexes of bacteriochlorophyll c with astaxanthin

Article Type: SI "Photosynthetic light harvesting"

Keywords: light-harvesting; chlorosomes; self-assembly; bacteriochlorophyll aggregates; astaxanthin

Corresponding Author: Jakub Psencik

Corresponding Author's Institution:

First Author: Jan Alster, M.Sc.

Order of Authors: Jan Alster, M.Sc.;Tomáš Polívka, Prof.;Juan B. Arellano, Dr.;Petr Hř́bek, Ing.;František Vácha, Prof.;Jan Hála, Prof.;Jakub Psencik

Abstract: Chlorosomes, the light harvesting antennas of green photosynthetic bacteria, are based on large aggregates of bacteriochlorophyll molecules. Aggregates with similar properties to those in chlorosomes can also be prepared in vitro. Several agents were shown to induce aggregation of bacteriochlorophyll $\mathrm{c}$ in aqueous environments, including certain lipids, carotenes and quinones. A key distinguishing feature of bacteriochlorophyll c aggregates, both in vitro and in chlorosomes, is a large $(>60 \mathrm{~nm}$ ) red shift of their Qy absorption band compared with that of the monomers. In this work, we study the self-assembly of bacteriochlorophyll $\mathrm{c}$ with the xantophyll astaxanthin, which leads to the formation of a new type of complexes. Our results indicate that, due to its specific structure, astaxanthin molecules competes with bacteriochlorophylls for the bonds involved in the aggregation, thus preventing formation of any significant red shift compared to pure bacteriochlorophyll $\mathrm{c}$ in aqueous buffer. A strong interaction between both types of pigments in the developed assemblies is manifested by a rather efficient ( $\sim 40 \%)$ energy transfer from astaxanthin to bacteriochlorophyll c, as revealed by fluorescence excitation spectroscopy. Results of transient absorption spectroscopy show that the energy transfer is very fast ( $<500 \mathrm{fs})$ and proceeds via the $\mathrm{S} 2$ state of astaxanthin. 


\title{
Self-assembly and energy transfer in artificial light-harvesting complexes of bacteriochlorophyll $c$ with astaxanthin
}

\author{
J. Alster ${ }^{\mathrm{a}}$, T. Polívka ${ }^{\mathrm{b}, \mathrm{c}}$, J. B. Arellano ${ }^{\mathrm{d}}$, P. Hř́bek ${ }^{\mathrm{b}}$, F. Vácha ${ }^{\mathrm{b}, \mathrm{c}}$, J. Hála $^{\mathrm{a}}$, J. Pšenčík ${ }^{\mathrm{a}, \mathrm{b}, *}$
}

${ }^{a}$ Faculty of Mathematics and Physics, Charles University, Ke Karlovu 3, 12116 Praha, Czech Republic ${ }^{\mathrm{b}}$ Institute of Physical Biology, University of South Bohemia, Zámek 136, 37333 Nové Hrady, Czech Republic

${ }^{c}$ Biology Centre, Academy of Sciences of the Czech Republic, Branišovská 31, 37005 České Budějovice, Czech Republic

${ }^{\mathrm{d} I n s t i t u t o ~ d e ~ R e c u r s o s ~ N a t u r a l e s ~ y ~ A g r o b i o l o g i ́ a ~ d e ~ S a l a m a n c a ~(I R N A S A-C S I C), ~ A p d o . ~ 257, ~} 37071$ Salamanca, Spain

* corresponding author; e-mail: psencik@karlov.mff.cuni.cz, tel.: (+420) 221911 248, fax: (+420) 221 911249

Chlorosomes, the light harvesting antennas of green photosynthetic bacteria, are based on large aggregates of bacteriochlorophyll molecules. Aggregates with similar properties to those in chlorosomes can also be prepared in vitro. Several agents were shown to induce aggregation of bacteriochlorophyll $c$ in aqueous environments, including certain lipids, carotenes and quinones. A key distinguishing feature of bacteriochlorophyll $c$ aggregates, both in vitro and in chlorosomes, is a large (>60 nm) red shift of their $\mathrm{Q}_{\mathrm{y}}$ absorption band compared with that of the monomers. In this work, we study the self-assembly of bacteriochlorophyll $c$ with the xantophyll astaxanthin, which leads to the formation of a new type of complexes. Our results indicate that, due to its specific structure, astaxanthin molecules competes with bacteriochlorophylls for the bonds involved in the aggregation, thus preventing formation of any significant red shift compared to pure bacteriochlorophyll $c$ in aqueous buffer. A strong interaction between both types of pigments in the developed assemblies is manifested by a rather efficient $(\sim 40 \%)$ energy transfer from astaxanthin to bacteriochlorophyll $c$, as revealed by fluorescence excitation spectroscopy. Results of transient absorption spectroscopy show that the energy transfer is very fast ( $<500 \mathrm{fs}$ ) and proceeds via the $\mathrm{S}_{2}$ state of astaxanthin.

Keywords: light-harvesting; chlorosomes; self-assembly; bacteriochlorophyll aggregates; astaxanthin 


\section{Introduction}

Chlorosomes of green photosynthetic bacteria (Blankenship and Matsuura 2003; Frigaard and Bryant 2006) contain large aggregates of bacteriochlorophyll (BChl) $c, d$ or $e$ molecules arranged into curved lamellar structures (Psencik et al. 2004; Psencik et al. 2006; Oostergetel et al. 2007; Ganapathy et al. 2009; Psencik et al. 2009; Oostergetel et al. 2010). The BChl aggregates are held together by interactions between the central $\mathrm{Mg}$ ion of one $\mathrm{BChl}$ molecule, a hydroxyl group at $\mathrm{C} 3^{1}$ of another BChl and a keto group at $\mathrm{C} 13^{1}$ of a third BChl molecule (Hildebrandt et al. 1994; Balaban 2005). The close interaction between BChl molecules leads to strong exciton coupling which is manifested by a large red shift of the $\mathrm{Q}_{\mathrm{y}}$ absorption band. Carotenoids and quinones are also present in the chlorosomes, occupying the hydrophobic space between the lamellar layers of BChls (Psencik et al. 2006). Carotenoids in chlorosomes are involved in both light-harvesting and photoprotection (Melo et al. 2000; Psencik et al. 2002; Polivka and Frank 2010); whereas quinones mediate a protective quenching of the excitation energy in chlorosomes of green sulfur bacteria in the presence of oxygen (Frigaard et al. 1997). A chlorosome envelope is thought to be formed by a monolayer of lipids; it covers all of the chlorosome surface except the region where the chlorosome is attached to the cytoplasmic membrane. On this side, the chlorosome is delimited by a paracrystalline baseplate composed of CsmA proteins, which bind BChl $a$ and carotenoids(Sakuragi et al. 1999; Bryant et al. 2002; Montano et al. 2003; Pedersen et al. 2008).

Aggregates of chlorosomal BChls or their synthetic analogues can also be prepared in vitro, either in non-polar or polar environments (for reviews see Balaban et al. 2005; Miyatake and Tamiaki 2005; Miyatake and Tamiaki 2010). In polar environments, e.g. aqueous solutions, the aggregation of $\mathrm{BChl} c$ is driven by hydrophobic interactions (Klinger et al. 2004; Zupcanova et al. 2008). Addition of a suitable non-polar component is necessary to induce aggregation, most likely because hydrophobic interactions between farnesyl tails of $\mathrm{BChl} c$ molecules alone are not sufficiently strong to drive it. Lipids are well-known to play such an inducing effect on BChl $c$ aggregation (Hirota et al. 1992; Uehara et al. 1994; Steensgaard et al. 2000), but there are other molecules that also induce aggregation of BChl $c$ in aqueous solutions, for example, quinones with a hydrophobic side-chain (Alster et al. 2008) or carotenes such as chlorobactene (Klinger et al. 2004) and $\beta$-carotene (Alster et al. 2010). Each of these additional components affects the properties of the formed assemblies in a distinct way. Aggregates with quinones exhibit redox-dependent quenching of the BChl $c$ excitation (Alster et al. 2008); whereas energy transfer from carotenoid to BChl $c$ was observed in aggregates with $\beta$-carotene (Alster et al. 2010). The energy transfer proceeds mainly via the carotenoid $S_{2}$ state, i.e. in a manner 
similar to that in chlorosomes (Psencik et al. 2002), except that the efficiency of energy transfer in the aggregates ( 30\%) was lower than in chlorosomes (50-80\%, (Melo et al. 2000; Psencik et al. 2002)).

In this contribution, properties of assemblies of BChl $c$ with the xanthophyll astaxanthin are studied by the steady-state and fs time-resolved spectroscopy. Astaxanthin is characterized by the presence of one hydroxyl group and a keto group in each of its end $\beta$-rings, giving unusual features to

the assemblies of BChl $c$ when they are compared with all other successfully tested admixtures. In fact, astaxanthin does not induce any pronounced red shift of the $\mathrm{BChl} c \mathrm{Q}_{\mathrm{y}}$ band, but it closely interacts with the BChl $c$ molecules, forming assemblies. Astaxanthin in the assemblies is capable of energy transfer to BChl $c$. Compared to previously tested carotenoids, assemblies of BChl $c$ with astaxanthin exhibit an improved absorption in the spectral range between 500-600 nm, where BChl $c$ absorbs poorly. This makes these assemblies interesting for potential use in artificial photosynthesis.

\section{Materials and Methods}

Sample Preparation

BChl $c$ (Figure 1a) was extracted from whole cells of the green sulfur bacterium Chlorobaculum tepidum (formerly known as Chlorobium tepidum) and purified by means of HPLC as described previously (Klinger et al. 2004). The four main homologues of BChl $c$ were collected together, in the same ratio as they were isolated from chlorosomes. Astaxanthin (Figure 1b) was purchased from Sigma and was used without further purification. Assemblies of BChl $c$ with or without astaxanthin were prepared by mixing stock solutions of astaxanthin (in THF) and BChl $c$ (in methanol) to reach several molar ratios of astaxanthin to $\mathrm{BChl} c$ within a range of $0.0-0.8$ to 1.0 . This mixture was then injected into stirred $50 \mathrm{mM}$ Tris- $\mathrm{HCl} \mathrm{pH} 8.0$ buffer. The final concentration of BChl $c$ and the percentage of organic solvents in the buffer were approximately $30 \mu \mathrm{M}$ and $<1 \%(\mathrm{v} / \mathrm{v})$ for self-assembly experiments and $250 \mu \mathrm{M}$ and 3-4\% (v/v) for transient absorption spectroscopy, respectively. Pigment concentrations were determined from absorption spectra, using the extinction coefficients of $70 \mathrm{mM}^{-1} \mathrm{~cm}^{-1}$ for BChl $c$ in methanol at the $\mathrm{Q}_{\mathrm{y}}$ maximum (Stanier and Smith 1960) and $125 \mathrm{mM}^{-1} \mathrm{~cm}^{-1}$ determined for the absorption maximum of astaxanthin in hexane (Weber 1988). Samples were left overnight in dark at room temperature to reach stable steady-state absorption spectra. Samples were gently homogenized in a water bath sonicator before measurement to avoid precipitates.

\section{Optical spectroscopy}

Steady-state absorption spectra were measured using a Specord 250 spectrophotometer (Analytic Jena). 
Absorption spectra were corrected for scattering by measuring absorption spectra at two different distances from detector. The difference spectra (Figure S1) yielded the spectral profile of the lightscattering of the sample (Latimer and Eubanks 1962), which, in turn, was used for the calculation of correction curves also for other samples of the same pigment composition. This approximation worked reasonably well even for samples with significantly different concentrations. The correction for a possible sieve effect was not performed.

Fluorescence excitation spectra were measured using a FluoroMax-2 fluorescence spectrometer (Jobin Yvon - Spex). The fluorescence excitation spectra were corrected for the wavelength dependence of the excitation light intensity. The correction was done by measuring the intensity of the excitation light at the sample place by a calibrated diode power meter FieldMaster-GS (Coherent) with sensors LM-2-UV (in the region between 250-400 nm) and LM-2-VIS (400-800 nm ). The second order of the excitation light and contribution of the stray light was attenuated by using a $715 \mathrm{~nm}$ cut-off filter (Roper Scientific). The remaining contribution of the stray light above $715 \mathrm{~nm}$ was measured separately and subtracted from the excitation spectra. Optical density of the samples was adjusted to $\sim 0.15$ at the $\mathrm{Q}_{\mathrm{y}}$ maximum of $\mathrm{BChl} c$ to minimize the reabsorption of the emitted photons.

A set-up for femtosecond transient absorption measurements was based on an amplified laser system Integra-i (Quantronix), consisting of Er-fiber oscillator and Ti:Sapphire amplifier. It was used as a source of $\sim 120 \mathrm{fs}$ pulses centered at $786 \mathrm{~nm}$ at a repetition rate of $1 \mathrm{kHz}$. Excitation pulses were obtained by directing a part of the amplifier output to the optical parametric amplifier (TOPAS, Light Conversion). A fraction of the $786 \mathrm{~nm}$ beam was focused to a $2 \mathrm{~mm}$ sapphire plate where it generated broadband white-light pulses. The white-light pulses were further divided into the probe beam that overlapped with the excitation beam at the sample, and a reference beam. A spectrograph equipped with a double photodiode array (1024 elements) was used as a detector for both probe and reference beams. This arrangement allowed measurements of transient spectra in a spectral window of $\sim 240 \mathrm{~nm}$. In all measurements the mutual polarization of pump and probe beams was set to the magic angle $\left(54.7^{\circ}\right)$ by placing a polarization rotator in the pump beam. Instrument response function was estimated on the basis of the onset of instantaneous bleaching signal to be Gaussian with the full width at half maximum of $150 \mathrm{fs}$. Sample was placed in a rotating cuvette consisting of two $1 \mathrm{~mm}$ quartz windows separated by a $1 \mathrm{~mm}$ Teflon spacer. Excitation intensities of $\sim 4 \times 10^{14}$ photons pulse $\mathrm{cm}^{-2}(450-490$ $\mathrm{nm})$ and $\sim 10^{15}$ photons pulse $\mathrm{cm}^{-1}(710 \mathrm{~nm})$ were used. Steady-state absorption spectra were measured before and after the experiments to ensure that no degradation occurred during the data acquisition. Spectral bands did not change their shape during experiments, but overall decrease of absorbance about 
$5 \%$ occurred in some measurement. This is likely due to precipitation which is the consequence of the assembly formation and is further described in the Results.

\section{Results}

\section{Self-assembly experiments}

In contrast to other chlorophyll-like molecules, pure $\mathrm{BChl} c$ is partly soluble in aqueous buffer in a form with an absorption spectrum basically identical to that of an antiparallel piggy-back dimer, as determined by $\mathrm{NMR}$ in $\mathrm{CH}_{2} \mathrm{Cl}_{2}$ (Umetsu et al. 2003). This form is characterized by a $\mathrm{Q}_{\mathrm{y}}$ absorption maximum between 710 and $715 \mathrm{~nm}$ and two weaker peaks or shoulders at $\sim 680$ and $635 \mathrm{~nm}$, and is denoted as 'dimers' throughout this study.

Figure 2 compares the steady-state absorption spectra of pure BChl $c$ in aqueous buffer (i.e. dimers) with those of BChl $c$ assemblies with varying amounts of admixed astaxanthin. These spectra differ markedly from those of BChl $c$ aggregates with lipids, carotenes or quinones, which were shown to induce aggregation of $\mathrm{BChl} c$ in aqueous solutions. The main difference is that astaxanthin does not induce any pronounced red shift of the $\mathrm{BChl} c \mathrm{Q}_{\mathrm{y}}$ band, instead the band remains at a position comparable to that of BChl $c$ dimers $(\sim 715 \mathrm{~nm})$.

Like BChl $c$, astaxanthin is not freely soluble in aqueous buffer, but it can remain dispersed at low concentrations in buffer if it is first dissolved in a small amount of THF, and then injected into the buffer in a way similar to the method used for the preparation of BChl $c$ assemblies. Despite this, we can exclude that the $\mathrm{BChl} c$ assemblies with astaxanthin consist of a mixture of $\mathrm{BChl} c$ dimers and free astaxanthin dissolved in the buffer. The most compelling evidence of incorporation of astaxanthin into BChl $c$ assemblies comes from the analysis of the astaxanthin-to-BChl $c$ energy transfer (see below), but several other arguments arise from a closer inspection of the absorption spectra of the assemblies.

Firstly, although some precipitation occurs for any BChl $c$ assembly with astaxanthin, it is significantly slower for samples with high pigment content containing both $\mathrm{BChl} c$ and astaxanthin than for the pure pigments dissolved in the buffer separately (i.e. BChl $c$ and astaxanthin assemblies are soluble in aqueous buffer in higher concentrations than pure pigments). This cooperation is effective only up to a molar ratio of $\sim 0.35: 1$ (astaxanthin to $\mathrm{BChl} c$ ), which is the highest pigment molar ratio achieved without a significant precipitation. In addition, the assemblies of BChl $c$ with astaxanthin exhibit slightly enhanced amplitude of the monomer-like BChl $c$ absorption at $\sim 675 \mathrm{~nm}$ compared with

BChl $c$ dimers, and its relative intensity increases with the astaxanthin concentration in the sample. It should be noted that monomeric bacteriochlorophyllide $c$, whose absorption spectrum is the same as 
that of BChl $c$ (e.g. in methanol), is soluble in aqueous buffer and has its absorption maximum at 675 $\mathrm{nm}$ (Zupcanova et al. 2008). Therefore, it is expected that monomer-like BChl $c$ in buffer would also have an absorption maximum at $675 \mathrm{~nm}$. To emphasize the structural difference with aggregates of BChl $c$ with lipids, carotenes or quinones, we call the formed complexes with astaxanthin 'assemblies' instead of 'aggregates'.

The formation of $\mathrm{BChl} c$-astaxanthin assemblies also led to an increase of the light-scattering by the samples. For the comparison with the fluorescence excitation spectra, and in order to determine the number of excited molecules at several wavelengths in the time resolved experiments, the correction of the absorption spectra for scattering was required (as described in Materials and Methods). As the absorption of $\mathrm{BChl} c$ in the Soret region overlaps with that of astaxanthin, it is not straightforward to determine the number of photons absorbed by each of the pigments in the $\mathrm{BChl} c$-astaxanthin assemblies at a given wavelength. However, it can be done if the absorption spectrum of the assemblies is compared with the one of $\mathrm{BChl} c$ dimers and the contribution of the $\mathrm{BChl} c$ dimers is subtracted. Figure 3 shows difference spectra between absorption spectra of BChl $c$-astaxanthin assemblies with variable astaxanthin content and $\mathrm{BChl} c$ dimers. The difference spectra reflect the contribution of astaxanthin to each of the absorption spectra. A comparison of the difference spectra with the absorption spectrum of astaxanthin in THF (Figure 3) shows that the main absorption peak of astaxanthin in assemblies is broader and shifted to longer wavelengths, similarly as observed in artificial aggregates of BChl $c$ with $\beta$-carotene and native chlorosomes (Arellano et al. 2000; Alster et al. 2010). In addition, the band at $\sim 300 \mathrm{~nm}$ is more pronounced for astaxanthin in BChl $c$ assemblies. Besides the contribution of astaxanthin to the difference spectrum, other minor contributions come from the changes in the Soret band ( 400-450 nm) and Qy band (700-750nm) of BChl $c$ upon formation of the assemblies with astaxanthin.

\section{Excitation spectra}

Fluorescence excitation spectra were measured in order to determine whether astaxanthin in the assemblies was able to transfer energy to BChl $c$. Figure 4 compares the absorption (1-T) spectrum, corrected for the light-scattering, with the fluorescence excitation spectrum detected at $770 \mathrm{~nm}$.

Excitation spectrum exhibited clear features of the astaxanthin absorption (a pronounced shoulder at around $525 \mathrm{~nm}$ ), clearly demonstrating that excitation energy is transferred from astaxanthin to $\mathrm{BChl} c$. The quantum efficiency of the transfer could be determined by comparison with the absorption (1-T) spectrum of BChl $c$ dimers. The difference between the absorption (1-T) spectra of BChl $c$ assemblies 
with astaxanthin and $\mathrm{BChl} c$ dimers reflected the total astaxanthin absorption in the sample (similarly as in Figure 3). On the other hand, the difference spectrum between absorption and excitation spectrum of the BChl $c$ assemblies with astaxanthin revealed the portion of the photons absorbed by astaxanthin and not transferred to $\mathrm{BChl} c$. In Figure 4, it can be clearly seen that also the latter difference spectrum resembles the astaxanthin absorption in the sample, including the band at $300 \mathrm{~nm}$. The quantum efficiency of the energy transfer from astaxanthin to BChl $c$ could be determined from these spectra. The assessment was complicated by the accompanying changes in the BChl $c$ Soret band upon the formation of the assemblies, mainly in the spectral range between 400-450 $\mathrm{nm}$. This contributed to a rather large uncertainty of the determined efficiency, which was found to be $40 \pm 7 \%$, taking into account both measurement errors and confidence of corrections.

\section{Transient absorption}

To determine the kinetics and pathways of the excitation energy transfer from astaxanthin, transient absorption spectra for the $\mathrm{BChl} c$ assemblies with astaxanthin were recorded. Additionally, the transient absorption spectra of samples without astaxanthin were measured for comparison purposes and determination of relaxation processes in $\mathrm{BChl} c$ not affected by the presence of astaxanthin. Unfortunately, BChl $c$ dimers quickly precipitate after preparation at the concentration needed for transient absorption measurements. Therefore, a small amount of lecithin $(\leq 0.1 \mathrm{~mol} / \mathrm{mol}$ lecithin to BChl c) was added to the BChl $c$ dissolved in methanol before injection into the buffer, which prevented (fast) precipitation of the sample and led to a negligible shift of the $\mathrm{Q}_{\mathrm{y}}$ absorption band compared to $\mathrm{BChl} c$ dimers. This sample is hereafter referred to as $\mathrm{BChl} c$ dimers with lecithin.

Transient spectra were measured after excitation at three different excitation wavelengths: 450, 490 and $710 \mathrm{~nm}$. Excitation at $710 \mathrm{~nm}$ was used to check whether there was any significant exciton coupling between BChl $c$ and astaxanthin. In such a case, transient changes in the region of astaxanthin photobleaching or stimulated emission (PB/SE) would be expected, even though at $710 \mathrm{~nm}$ only BChl $c$ is excited. However, transient spectra of samples with astaxanthin differed only slightly from those with lecithin by a weak signal (4\% of the $\mathrm{PB} / \mathrm{SE}$ signal amplitude in the $\mathrm{BChl} c \mathrm{Q}_{\mathrm{y}}$ region, not shown) observed in the region of astaxanthin PB/SE. Such a small difference excludes any significant exciton coupling between BChl $c$ and astaxanthin in our samples.

To determine the pathway of the energy transfer from astaxanthin to $\mathrm{BChl} c$, which was revealed by excitation spectra, two excitation wavelengths were used: Soret band of BChl $c$ was preferentially excited at $450 \mathrm{~nm}$ and astaxanthin at $490 \mathrm{~nm}$. However, strictly speaking, both pigments 
were excited at both wavelengths, although in a different ratio. Figure 5 shows the transient spectra of BChl $c$ assemblies with astaxanthin (astaxanthin-to-BChl $c$ molar ratio of 0.2:1) after excitation at 490nm. Transient signal under $\sim 550 \mathrm{~nm}$ reflects mainly $\mathrm{PB} / \mathrm{SE}$ of the $\mathrm{S}_{2}$ state of astaxanthin, while excited state absorption (ESA) of the astaxanthin $\mathrm{S}_{1}$ state is dominating between $550-700 \mathrm{~nm}$, and $\mathrm{PB} / \mathrm{SE}$ of the BChl $c \mathrm{Q}_{\mathrm{y}}$ band above $700 \mathrm{~nm}$. Similar results were also obtained for a sample with an astaxanthin-to-BChl $c$ molar ratio of 0.35:1. The lifetimes reported further in the text are representative values for all samples under study.

Assuming multi-exponential relaxation, the data can be analyzed by a global analysis (van Stokkum et al. 2004) which provides rate constants and pre-exponential factors (the decay associated spectra - DAS). This procedure reveals the most important relaxation processes occurring in the assemblies. However, this approach leads to a mixing of contributions from $\mathrm{BChl} c$ and astaxanthin states, which spectrally overlap and exhibit similar lifetimes. This complication can be avoided by separating transient data into two parts: relaxation following excitation of astaxanthin, and $\mathrm{BChl} c$, respectively (see Appendix). Subsequently global analysis was performed on both parts separately. As a consequence of the equations (A5), both parts of transient data are normalized to the same number of absorbed photons.

The astaxanthin part of the transient data (Figure 6a) retains almost all of the negative signal below $550 \mathrm{~nm}$, most of the positive signal around $600 \mathrm{~nm}$, and a part of the PB/SE of the BChl $c \mathrm{Q}_{\mathrm{y}}$ band. The transient data reveal that the decrease in the transient absorption of the astaxanthin $\mathrm{S}_{2}$ state $(<550 \mathrm{~nm})$ is connected with a concomitant rise of ESA signal around $620 \mathrm{~nm}$ (mainly from the astaxanthin $\mathrm{S}_{1}$ state) and $\mathrm{PB} / \mathrm{SE}$ signal in the $\mathrm{Q}_{\mathrm{y}}$ region of $\mathrm{BChl} c$. This process is reflected by the fastest component ( $140 \mathrm{fs})$ obtained from a global analysis performed on the xanthophyll part of transient data (Figure 6c), clearly showing energy transfer from astaxanthin to $\mathrm{BChl} c$.

The second fastest component has a lifetime of $\sim 0.5 \mathrm{ps}$ and an amplitude negative below $\sim 600$ $\mathrm{nm}$ and positive between $600-700 \mathrm{~nm}$. Such a lifetime and spectral profile are typical for vibrational relaxation within the $S_{1}$ state of carotenoids. For instance, the 0.6 ps component was attributed to vibrational relaxation in the $S_{1}$ state of astaxanthin bound to $\alpha$-crustacyanin (Ilagan et al. 2005). This and all subsequent components have also a minor contribution from the $\mathrm{PB} / \mathrm{SE}$ of the $\mathrm{BChl} c \mathrm{Q}_{\mathrm{y}}$ band. The global analysis mainly reflects the relaxation of dominating components (i.e. those of astaxanthin) and is not able to distinguish weaker components with similar lifetimes in the case of insufficient signal to noise ratio of the data. Therefore, more representative lifetimes for the decay of the BChl signal can be found in the BChl part of the transient data. Third component has a lifetime of $4.4 \mathrm{ps}$ and 
corresponds to the main decay of the $S_{1}$ state of astaxanthin.

The next component, with a lifetime of $\sim 14 \mathrm{ps,} \mathrm{is} \mathrm{dominated} \mathrm{by} \mathrm{a} \mathrm{peak} \mathrm{at} 560 \mathrm{~nm}$. A peak at similar position, although with a significantly shorter lifetime (1.9 ps) was observed for astaxanthin dissolved in carbon disulfide (Ilagan et al. 2005) and it was suggested that the signal is due to either a $\mathrm{S}^{*}$ state or excited state solvation. Though we observed much longer lifetime, it is worth noting that $\mathrm{S}^{*}$ lifetime of 7 ps was measured in a water-soluble analog of astaxanthin, astalysine (Chabera et al. 2010), indicating that the $S^{*}$ lifetime may be sensitive to environment. Consequently, we assign the 14 ps component to the $\mathrm{S}^{*}$ state of astaxanthin in the assemblies.

The last resolved component has a lifetime longer than the longest measured delay (130 ps) and, in the region of the astaxanthin signal, corresponds to relaxation of an ESA signal centered at $580 \mathrm{~nm}$. This long-lived ESA signal is assigned to an astaxanthin triplet-triplet absorption based on comparison with previous results on aggregates of $\mathrm{BChl} c$ with $\beta$-carotene, where a similar signal was centered at $550 \mathrm{~nm}$ (Alster et al. 2010). This assignment is further supported by observation of the triplet state of spheroidene and spheroidenone in reaction centres from Rhodobacter sphaeroides 2.41 and the mutant RCO2 (Arellano et al. 2004). The spheroidenone contains a keto group and shows a broader and red shifted triplet-triplet absorption spectrum compared to spheroidene, i.e. similar differences as observed between $\beta$-carotene and astaxanthin.

The BChl $c$ part of the transient data (Figure 6b), on the other hand, retained most of PB/SE signal in the $\mathrm{Q}_{\mathrm{y}}$ region of $\mathrm{BChl} c$ and some broad ESA signal between 550-680nm. As expected, it is very similar to the transient signal of BChl $c$ dimers with lecithin (Figure 5b). This corroborates the relevance of the decomposition method. The only difference is found in somewhat bigger amplitude of the ESA signal around 630nm in the $\mathrm{BChl}$ part of the transient data. Assuming no energy transfer from BChl $c$ to astaxanthin (see below), this signal must come from the xanthophyll contribution admixed to the BChl $c$ part of transient data during decomposition; this is most probably caused by small unavoidable errors in determining populations of initially excited states.

It may be expected that the fastest relaxation process observed within the $\mathrm{BChl} c$ part of the transient data is internal conversion from the Soret to $\mathrm{Q}_{\mathrm{y}}$ band. This process is connected with the fast increase of the SE signal of the $\mathrm{BChl} c \mathrm{Q}_{\mathrm{y}}$ band. It is also reflected as the fastest DAS component resolved by global analysis (Figure 6d), with a lifetime of $~ 100 \mathrm{fs}$. It should be stressed that this lifetime is shorter than the instrument response time; therefore it is determined with a rather high uncertainty and the spectral profile of this component most probably also contain some artifacts originating from coherent processes caused by excitation and/or the fact that the model used for global 
analysis does not account for a variable width of the excitation pulse over the whole spectral region. Thus the only conclusion we can draw is that the lifetime of internal conversion from the Soret to $\mathrm{Q}_{\mathrm{y}}$ band is up to $\sim 100$ fs.

The next two components revealed by global analysis have lifetimes of $\sim 0.4 \mathrm{ps}$, attributed to energy redistribution in the $\mathrm{BChl} c \mathrm{Q}_{\mathrm{y}}$ band, and 2.4ps, corresponding to the main decay of $\mathrm{BChl} c$. The last two components, with lifetimes of $18 \mathrm{ps}$ and $>130 \mathrm{ps}$, are due to the relaxation of $\mathrm{BChl} c$ to the ultimate acceptor state of the assembly. We cannot exclude that the relaxation within the BChl $c$ manifold is affected by annihilation, as observed in BChl aggregates in chlorosomes (Psencik et al. 2003). There is no signal which could be attributed to energy transfer from BChl $c$ to astaxanthin. This fact further supports an interpretation of the extraneous ESA around $610 \mathrm{~nm}$ in the BChl $c$ part of the transient data as an artifact of the transient data decomposition.

\section{Discussion}

In previous works, we have demonstrated that, in addition to lipids, specific carotenes and quinones induce aggregation of BChl $c$ in aqueous buffers (Klinger et al. 2004; Alster et al. 2008; Alster et al. 2010). The aggregation is manifested by a red shift of the $\mathrm{BChl} c \mathrm{Q}_{\mathrm{y}}$ transition, which increases with the concentration of the aggregation-inducing species. However, the xanthophyll astaxanthin used in this work behaves differently. The red shift of the $\mathrm{Q}_{\mathrm{y}}$ band of BChl $c$ upon addition of astaxanthin is nearly absent, indicating that the assemblies of BChl $c$ with astaxanthin are formed in a different manner. As the most plausible explanation we propose that the hydroxyl group of the astaxanthin end ring (Figure 1) competes for the Mg coordination with hydroxyl group of another BChl $c$. Similarly keto oxygen of the astaxanthin end ring and $\mathrm{BChl} c$ (Figure 1) may compete for hydrogen bonding with hydroxyl groups of both pigments. However, at this stage we do not have any direct evidence concerning the nature of interactions between astaxanthin and $\mathrm{BChl} c$.

The suggested involvement of astaxanthin in the hydrogen bonding pattern thus prevents the stacking of many BChl $c$ molecules, a prerequisite for their strong exciton coupling and, consequently, for the red shift of the $\mathrm{BChl} c \mathrm{Q}_{\mathrm{y}}$ band in the assemblies. It also explains the enhancement of the monomer-like peak in the absorption spectra, which certainly cannot originate from free monomers of BChl $c$ in buffer. The interference of the astaxanthin functional groups with those involved in the aggregation of $\mathrm{BChl} c$ may be the reason why xanthophylls are not usually found in chlorosomes, although hydroxyl chlorobactene or $\mathrm{OH}-\gamma$-carotene have been detected in minor amounts $(<2 \%$ of total carotenoid content) in cells of some strains of Chlorobaculum tepidum (Takaichi et al. 1997). 
Chlorosomal carotenoids, e.g. chlorobactene, posses neither keto nor hydroxyl groups, and interact with BChl $c$ mainly by hydrophobic and/or $\pi-\pi$ interaction. The difference spectra between the BChl $c$ assemblies with higher molar ratio of astaxanthin and BChl $c$ dimers indicate the presence of some aggregates absorbing at around $740 \mathrm{~nm}$ (judging from the wave-like pattern in the $\mathrm{Q}_{\mathrm{y}}$ band region; Figure 3), however, most of the BChl $c$ molecules exhibit spectral features of BChl $c$ dimers.

Compelling evidence of energy transfer from astaxanthin to $\mathrm{BChl} c$, with quantum efficiency of about $40 \%$, was obtained by fluorescence excitation spectra. Further support comes from the global analysis of the transient data, which revealed a fast component of $\sim 140$ fs following the excitation of astaxanthin with a spectral profile characteristic for energy transfer. This component indicates that the excitation absorbed by the $\mathrm{S}_{2}$ state of astaxanthin (PB/SE below $550 \mathrm{~nm}$ ) partly undergo relaxation into the astaxanthin $S_{1}$ state (arrival of the energy reflected by a negative amplitude of this component between 550-700 $\mathrm{nm}$ which corresponds to a rise of ESA) and partly to $\mathrm{BChl} c$, which is manifested by a positive amplitude above $700 \mathrm{~nm}$ (rise of $\mathrm{PB} / \mathrm{SE}$ ). In addition, the amplitudes of the transient data (PB/SE of the BChl $c \mathrm{Q}_{\mathrm{y}}$ band) decomposed into part following excitation of astaxanthin and BChl $c$ reflect the quantum efficiency of the astaxanthin-to-BChl $c$ energy transfer, which is consistent with that determined by fluorescence excitation spectra.

Support for the suggested energy transfer pathway in the BChl $c$ assemblies with astaxanthin can be found from the comparison of our transient data with some results derived from measurements of the S1 and S2 states lifetimes of astaxanthin in several solutions. Ilagan et al. (2005) determined the $\mathrm{S}_{1}$ state lifetime of astaxanthin in methanol, acetonitrile and carbon disulfide to be $\sim 5 \mathrm{ps}$, and the lifetime of $S_{2}$ state to be between 105 fs (methanol) and 165 fs (acetonitrile). Kopczynski et al. (2005) also reported a lifetime of $\sim 5 \mathrm{ps}$ for the $\mathrm{S}_{1}$ state of astaxanthin in various solutions ranging from toluene to methanol and a lifetime of $\leq 120$ fs for $S_{2}$ state of astaxanthin in acetone and dimethyl sulfoxide. The $\mathrm{S}_{2}$ state relaxation was also measured by photon echo spectroscopy for astaxanthin in THF and a lifetime of $160 \mathrm{fs}$ was determined using the excitation pulses of $\sim 30 \mathrm{fs}$ width (Christensson et al. 2009).

The lifetime of the $\mathrm{S}_{1}$ state of astaxanthin in assemblies with BChl $c$ was found to be 4.4 ps in this study. Such small shortening of the $S_{1}$ state lifetime compared to the lifetime in solution is at the edge of reliability, yet it may indicate a low efficiency $\mathrm{S}_{1}$-mediated energy transfer pathway to BChl $c$. However, as there is no rise component in the $\mathrm{BChl} c \mathrm{~PB} / \mathrm{SE}$ region matching the decay of astaxanthin $S_{1}$ state, we can safely conclude that $S_{1}$ pathway is closed in these assemblies and all energy transfer proceeds via the $S_{2}$ route. This conclusion is also corroborated by the fact that carotenoids with 
effective conjugation length comparable to astaxanthin (e.g. lycopene or spirilloxanthin) have $S_{1}$ energy below $13000 \mathrm{~cm}^{-1}$ (Billsten et al. 2002; Papagiannakis et al. 2003), thereby preventing energy transfer to $\mathrm{Q}_{\mathrm{y}}$ state of $\mathrm{BChl} c$ in the assemblies.

The $S_{2}$ state lifetime of astaxanthin, determined here, corresponds to the fastest component of the astaxanthin relaxation (140fs). Since astaxanthin-to-BChl $c$ energy transfer takes place in the assemblies, we must expect that the $\mathrm{S} 2$ state lifetime of astaxanthin becomes shorter in assemblies compared to that in solution. Using the lifetime of $160 \mathrm{fs}$ (Christensson et al. 2009), which fits within the uncertainty of $145 \pm 50 \mathrm{fs}$ obtained by Ilagan et al. (2005) in carbon disulfide, then, to ensure $40 \%$ efficiency determined by excitation spectra, the calculated energy transfer time is $240 \mathrm{fs}$. These values lead to the shortening of the $S_{2}$ state lifetime to $\sim 100 \mathrm{fs}$, which is shorter than the $S_{2}$ state lifetime in the presence of energy transfer determined by global analysis. However, the $S_{2}$ state lifetime is comparable with the instrument response time $(\sim 150 \mathrm{fs})$, and as such determined with a rather high uncertainty. On the other hand, the spectral shape of the $140 \mathrm{fs}$ DAS component clearly indicates energy transfer to $\mathrm{BChl} c$ and therefore the energy transfer observed by excitation spectra certainly occurs from the $\mathrm{S}_{2}$ state of astaxanthin and the energy transfer time should be less than $500 \mathrm{fs}$. It should be noted that fixing the lifetime of this component to $100 \mathrm{fs}$ does not affect DAS of this component and the change of the residues is below the noise level. The rather efficient and very fast energy transfer indicates that the BChl $c$ and astaxanthin form assemblies with a close distance between both pigments. This, together with other arguments reported in the Results section, excludes the possibility that our samples were just a mixture of dissolved BChl $c$ and astaxanthin.

The lifetimes reported above were determined from transient data decomposed into parts following excitation of astaxanthin and $\mathrm{BChl} c$, respectively, as described in Results. It should be stressed that standard global analysis applied to non-separated transient data leads to very similar results, but the main advantage of the decomposition is the very illustrative analysis of the relaxation after excitation either to $\mathrm{BChl} c$ or astaxanthin.

The fast formation of the triplet state excludes its origin in intersystem crossing, and suggests singlet homofission similarly as for the BChl $c$ aggregates with $\beta$-carotene (Alster et al. 2010). As described above, the $S_{1}$ lifetime of astaxanthin in the assemblies (4.4 ps) is slightly shorter than in solution ( $\sim 5 \mathrm{ps})$. Since it was concluded that this shortening cannot be due to energy transfer to BChl $c$, it is possible to speculate that the shortening is caused by additional weak relaxation channel leading to the triplet state formation by a singlet homofission mechanism with a quantum efficiency of $\sim 10 \%$. Alternatively, the triplet state may be formed by the homofission from the $S^{*}$ state, which was detected 
in the assemblies studied here. Since the $S^{*}$ state is known to be a precursor of the homofissiongenerated triplet state in some proteins containing carotenoids (Gradinaru et al. 2001), it is feasible that local environment of astaxanthin in the assemblies also provides favorable conditions for such pathway.

In conclusion, astaxanthin forms assemblies with $\mathrm{BChl} c$, which exhibit rather efficient and fast energy transfer from the $\mathrm{S}_{2}$ state of astaxanthin to $\mathrm{BChl} c$. Astaxanthin absorption in the assemblies covers mainly the spectral region between $500-550 \mathrm{~nm}$, filling a substantial part of the gap between the Soret and $\mathrm{Q}_{\mathrm{y}}$ band of $\mathrm{BChl} c$. As the $\mathrm{BChl} c$ assemblies with astaxanthin are formed by self-assembly, their absorption covers a substantial part of the visible spectrum, and are relatively stable, they might be an interesting model system for artificial light harvesting systems.

\section{Acknowledgements}

This study was supported by Czech Ministry of Education, Youth and Sports (projects MSM0021620835, MSM6007665808, AV0Z50510513), Czech Science Foundation (projects 206/09/0375, 202/09/H041, 202/09/1330) and Spanish Ministry of Science and Innovation (AVCRCSIC joint project 2008CZ0004). The authors would like to thank Ivana Hunalova, Frantisek Matousek and Anita Zupcanova for their help with pigment isolation.

\section{References}

Alster J, Polivka T, Arellano JB, Chabera P, Vacha F and Psencik J (2010) beta-Carotene to bacteriochlorophyll c energy transfer in self-assembled aggregates mimicking chlorosomes. Chem Phys 373: 90-97

Alster J, Zupcanova A, Vacha F and Psencik J (2008) Effect of quinones on formation and properties of bacteriochlorophyll c aggregates. Photosynth Res 95: 183-189

Arellano JB, Melo TB, Fyfe PK, Cogdell RJ and Naqvi KR (2004) Multichannel flash spectroscopy of the reaction centers of wild-type and mutant Rhodobacter sphaeroides: Bacteriochlorophyll $B^{-}$ mediated interaction between the carotenoids triplet and the special pair. Photochem Photobiol 79: $68-75$

Arellano JB, Psencik J, Borrego CM, Ma YZ, Guyoneaud R, Garcia-Gil J and Gillbro T (2000) Effect of carotenoid biosynthesis inhibition on the chlorosome organization in Chlorobium phaeobacteroides strain CL1401. Photochem Photobiol 71: 715-723

Balaban TS (2005) Tailoring porphyrins and chlorins for self-assembly in biomimetic artificial antenna 
systems. Acc Chem Res 38: 612-623

Balaban TS, Tamiaki H and Holzwarth AR (2005) Chlorins programmed for self-assembly. Top Curr Chem 258: 1-38

Billsten HH, Herek JL, Garcia-Asua G, Hashoj L, Polivka T, Hunter CN and Sundstrom V (2002)

Dynamics of energy transfer from lycopene to bacteriochlorophyll in genetically-modified LH2 complexes of Rhodobacter sphaeroides. Biochemistry 41: 4127-4136

Blankenship RE and Matsuura K (2003) Antenna complexes from green photosynthetic bacteria. In:

Green BR and Parson WW (eds) Light-harvesting antennas in photosynthesis, pp 195-217. Kluwer Academic Publishers, Dordrecht

Bryant DA, Vassilieva EV, Frigaard NU and Li H (2002) Selective protein extraction from Chlorobium tepidum chlorosomes using detergents. Evidence that CsmA forms multimers and binds bacteriochlorophyll $a$. Biochemistry 41: 14403-14411

Chabera P, Fuciman M, Naqvi KR and Polivka T (2010) Ultrafast dynamics of hydrophilic carbonyl carotenoids - Relation between structure and excited-state properties in polar solvents. Chem Phys 373: $56-64$

Christensson N, Polivka T, Yartsev A and Pullerits T (2009) Photon echo spectroscopy reveals structure-dynamics relationships in carotenoids. Physical Review B 79:

Frigaard NU and Bryant DA (2006) Chlorosomes: antenna organelles in photosynthetic green bacteria. In: Shively JM (ed) Complex Intracellular Structures in Prokaryotes (series: Microbiology Monographs, vol. 2), pp 79-114. Springer, Berlin

Frigaard NU, Takaichi S, Hirota M, Shimada K and Matsuura K (1997) Quinones in chlorosomes of green sulfur bacteria and their role in the redox-dependent fluorescence studied in chlorosome-like bacteriochlorophyll $c$ aggregates. Arch Microbiol 167: 343-349

Ganapathy S, Oostergetel GT, Wawrzyniak PK, Reus M, Chew AGM, Buda F, Boekema EJ, Bryant DA, Holzwarth AR and de Groot HJM (2009) Alternating syn-anti bacteriochlorophylls form concentric helical nanotubes in chlorosomes. Proc Natl Acad Sci 106: 8525-8530

Gradinaru CC, Kennis JTM, Papagiannakis E, van Stokkum IHM, Cogdell RJ, Fleming GR, Niederman RA and van Grondelle R (2001) An unusual pathway of excitation energy deactivation in carotenoids: Singlet-to-triplet conversion on an ultrafast timescale in a photosynthetic antenna. Proc Natl Acad Sci 98: 2364-2369

Hildebrandt P, Tamiaki H, Holzwarth AR and Schaffner K (1994) Resonance Raman-spectroscopic study of metallochlorin aggregates. Implications for the supramolecular structure in chlorosomal 
BChl c antennae of green bacteria. J Phys Chem 98: 2192-2197

Hirota M, Moriyama T, Shimada K, Miller M, Olson JM and Matsuura K (1992) High degree of organization of bacteriochlorophyll $c$ in chlorosome-like aggregates spontaneously assembled in aqueous solution. Biochim Biophys Acta 1099: 271-274

Ilagan RP, Christensen RL, Chapp TW, Gibson GN, Pascher T, Polivka T and Frank HA (2005)

Femtosecond time-resolved absorption spectroscopy of astaxanthin in solution and in alphacrustacyanin. J Phys Chem A 109: 3120-3127

Klinger P, Arellano JB, Vacha FE, Hala J and Psencik J (2004) Effect of carotenoids and monogalactosyl diglyceride on bacteriochlorophyll $c$ aggregates in aqueous buffer: Implications for the self-assembly of chlorosomes. Photochem Photobiol 80: 572-578

Kopczynski M, Lenzer T, Oum K, Seehusen J, Seidel MT and Ushakov VG (2005) Ultrafast transient lens spectroscopy of various C-40 carotenoids: lycopene, beta-carotene, (3R,3 ' R)- zeaxanthin, (3R,3 ' R,6 ' R)-lutein, echinenone, canthaxanthin, and astaxanthin. Phys Chem Chem Phys 7: 2793 2803

Latimer P and Eubanks CAH (1962) Absorption Spectrophotometry of Turbid Suspensions - A Method of Correcting for Large Systematic Distortions. Arch Biochem Biophys 98: 274-285

Melo TB, Frigaard NU, Matsuura K and Naqvi KR (2000) Electronic energy transfer involving carotenoid pigments in chlorosomes of two green bacteria: Chlorobium tepidum and Chloroflexus aurantiacus. Spectrochim Acta A Mol Biol Spectrosc 56: 2001-2010

Miyatake T and Tamiaki H (2005) Self-aggregates of bacteriochlorophylls-c, $d$ and e in a lightharvesting antenna system of green photosynthetic bacteria: Effect of stereochemistry at the chiral 3(1-hydroxyethyl) group on the supramolecular arrangement of chlorophyllous pigments. J Photoch Photobio C 6: 89-107

Miyatake T and Tamiaki H (2010) Self-aggregates of natural chlorophylls and their synthetic analogues in aqueous media for making light-harvesting systems. Coord Chem Rev 254: 2593-2602

Montano GA, Wu HM, Lin S, Brune DC and Blankenship RE (2003) Isolation and characterization of the B798 light-harvesting baseplate from the chlorosomes of Chloroflexus aurantiacus. Biochemistry 42: 10246-10251

Oostergetel GT, Reus M, Gomez Maqueo Chew A, Bryant DA, Boekema EJ and Holzwarth AR (2007) Long-range organization of bacteriochlorophyll in chlorosomes of Chlorobium tepidum investigated by cryo-electron microscopy. FEBS Lett 581: 5435-5439

Oostergetel GT, van Amerongen H and Boekema EJ (2010) The chlorosome: a prototype for efficient 
light harvesting in photosynthesis. Photosynth Res 104: 245-255

Papagiannakis E, van Stokkum IHM, van Grondelle R, Niederman RA, Zigmantas D, Sundstrom V and Polivka T (2003) A near-infrared transient absorption study of the excited-state dynamics of the carotenoid spirilloxanthin in solution and in the LH1 complex of Rhodospirillum rubrum. J Phys Chem B 107: 11216-11223

Pedersen MO, Underhaug J, Dittmer J, Miller M and Nielsen NC (2008) The three-dimensional structure of CsmA: A small antenna protein from the green sulfur bacterium Chlorobium tepidum. FEBS Lett 582: 2869-2874

Polivka T and Frank HA (2010) Molecular Factors Controlling Photosynthetic Light Harvesting by Carotenoids. Acc Chem Res 43: 1125-1134

Psencik J, Arellano JB, Ikonen TP, Borrego CM, Laurinmaki PA, Butcher SJ, Serimaa RE and Tuma R (2006) Internal structure of chlorosomes from brown-colored Chlorobium species and the role of carotenoids in their assembly. Biophys J 91: 1433-1440

Psencik J, Collins AM, Liljeroos L, Torkkeli M, Laurinmaki P, Ansink HM, Ikonen TP, Serimaa RE, Blankenship RE, Tuma R and Butcher SJ (2009) Structure of chlorosomes from the green filamentous bacterium Chloroflexus aurantiacus. J Bacteriol 191: 6701-6708

Psencik J, Ikonen TP, Laurinmäki P, Merckel MC, Butcher SJ, Serimaa RE and Tuma R (2004) Lamellar organization of pigments in chlorosomes, the light harvesting complexes of green photosynthetic bacteria. Biophys J 87: 1165-1172

Psencik J, Ma YZ, Arellano JB, Garcia-Gil J, Holzwarth AR and Gillbro T (2002) Excitation energy transfer in chlorosomes of Chlorobium phaeobacteroides strain CL1401: the role of carotenoids. Photosynth Res 71: 5-18

Psencik J, Ma YZ, Arellano JB, Hala J and Gillbro T (2003) Excitation energy transfer dynamics and excited-state structure in chlorosomes of Chlorobium phaeobacteroides. Biophys J 84: 1161-1179

Sakuragi Y, Frigaard NU, Shimada K and Matsuura K (1999) Association of bacteriochlorophyll $a$ with the CsmA protein in chlorosomes of the photosynthetic green filamentous bacterium Chloroflexus aurantiacus. BBA-Bioenergetics 1413: 172-180

Stanier RY and Smith JHC (1960) The chlorophylls of green bacteria. Biochim Biophys Acta 41: 478484

Steensgaard DB, Wackerbarth H, Hildebrandt P and Holzwarth AR (2000) Diastereoselective control of bacteriochlorophyll $e$ aggregation. 3(1)-S-BChl $e$ is essential for the formation of chlorosome-like aggregates. J Phys Chem B 104: 10379-10386 
Takaichi S, Wang ZY, Umetsu M, Nozawa T, Shimada K and Madigan MT (1997) New carotenoids from the thermophilic green sulfur bacterium Chlorobium tepidum: 1',2'-dihydro-gamma-carotene, 1',2'- dihydrochlorobactene, and $\mathrm{OH}$-chlorobactene glucoside ester, and the carotenoid composition of different strains. Arch Microbiol 168: 270-276

Uehara K, Mimuro M, Ozaki Y and Olson JM (1994) The formation and characterization of the in-vitro polymeric aggregates of bacteriochlorophyll $c$ homologs from Chlorobium limicola in aqueous suspension in the presence of monogalactosyl diglyceride. Photosynth Res 41: 235-243

Umetsu M, Seki R, Kadota T, Wang ZY, Adschiri T and Nozawa T (2003) Dynamic exchange properties of the antiparallel bacteriochlorophyll $c$ dimers. J Phys Chem B 107: 9876-9882

van Stokkum IHM, Larsen DS and van Grondelle R (2004) Global and target analysis of time-resolved spectra. BBA-Bioenergetics 1657: 82-104

Weber S (1988) Determination of stabilised, added astaxanthin in fish feeds and premixes with HPLC.

In: Keller HE (ed) Analytical Methods for Vitamins and Carotenoids in Feeds, pp 59-61. Roche Publication No. 2264, Basel

Zupcanova A, Arellano JB, Bina D, Kopecky J, Psencik J and Vacha F (2008) The length of esterifying alcohol affects the aggregation properties of chlorosomal bacteriochlorophylls. Photochem Photobiol 84: 1187-1194

\section{Appendix A. Transient data analysis}

We assume simple kinetic model for excited state population $\mathrm{N}_{\mathrm{i}}$

$$
\dot{N}_{i}(t)=-\sum_{i} k_{i j} N_{j}(t)
$$

where $k_{i j}$ is the rate constant for energy/population transfer from the state $i$ to the state $j$ and dot represents derivative with respect to time. By solving set of equations A1 (one for each state) and considering that each state contributes to transient signal proportionally to its population, we get the following model for describing transient absorption data

$$
\Delta A(t)=\sum_{j}\left(\sum_{i} K_{j i} \varepsilon_{i} N_{i}(0)\right) \exp \left(-k_{j} t\right)
$$

where $j, i$ iterates over all energy states present in the sample, $k_{j}$ is overall rate constant of the state $\mathrm{j}$

$$
\left.k_{j}=\sum_{i} k_{i j}\right), \varepsilon \text { is a spectral profile associated with the given state, and coefficients } K_{i j} \text { describe energy }
$$


transfer between states, typically $K_{i j}=\frac{k_{i j}}{k_{j}-k_{i}}$ or product of similar terms. We can then perform global analysis, i.e. fit this model on the data resulting in overall rate constants and corresponding preexponential factors (the decay associated spectra - DAS)

$$
\Delta A(t)=\sum_{j} D A S_{j} \exp \left(-k_{j} t\right)
$$

Let's assume in accordance with the multi-exponential model that relaxation pathways from an excited state are the same regardless of its population. This is of course an approximation, because relaxation within the BChl $c$ manifold is likely to be influenced by singlet-singlet annihilation which the model does not describe. It follows that the transient signal consists of parts proportional to the initial population of states directly excited by pump pulse (the other way of summation in A2)

$$
\Delta A(t)=\sum_{i}\left(\varepsilon_{i} \sum_{j} K_{j i} \exp \left(-k_{j} t\right)\right) N_{i}(0)=\sum_{i} \Delta a_{i} N_{i}(0)
$$

If we perform at least $\mathrm{P}$ measurements with different ratio of initial population of excited states, where $P$ is the number of the initially excited states (with non-zero $\mathrm{N}_{\mathrm{i}}(0)$ ), we can determine the parts of transient data corresponding to the relaxation from each of the initially excited states ( $\Delta a_{i}$ in equation A4). Note that these parts should be the same in all measurements, only their weight differs. Here we assume that only the $S_{2}$ state of astaxanthin and Soret band of BChl $c$ are directly excited, and the transient data separates into two parts: relaxation following excitation of astaxanthin, and BChl $c$, respectively. Therefore we need to perform two transient absorption measurements with a different ratio between initial populations of the $\mathrm{S}_{2}$ state of astaxanthin and the Soret band of $\mathrm{BChl} c$. One theoretically possible way to change excited state population is to use one excitation wavelength and two samples with different astaxanthin to $\mathrm{BChl} c$ molar ratios. However, different sample composition in this case results in different way of assembly and therefore in different absorption spectra, breaking the condition that relaxation from excited state is the same. The other way is to use one sample and two different excitation wavelengths (close enough to excite the same electronic transition and far enough to achieve significant change of excited populations ratio). In this case we populate different parts from the inhomogeneously broadened electronic transition peaks; this however should not influence relaxation from the higher excited state significantly. We measured transient data after excitation at two different wavelengths, 450 and $490 \mathrm{~nm}$; therefore, we can rewrite the equation (A4) describing global decay at two excitation wavelength as 


$$
\begin{aligned}
\Delta A_{450} & =\Delta a_{B C h l} N_{450}^{B C h l}(0)+\Delta a_{C a r} N_{450}^{C a r}(0) \\
\text { A5) } \quad \Delta A_{490} & =\Delta a_{B C h l} N_{490}^{B C h l}(0)+\Delta a_{C a r} N_{490}^{C a r}(0)
\end{aligned}
$$

where $\Delta A_{450}$ and $\Delta A_{490}$ represent transient data after excitation at 450 and $490 \mathrm{~nm}$, respectively. The initial excited state populations $N_{\lambda}{ }^{\text {molecule }}(0)$ could be determined directly from steady-state absorption spectra corrected for scattering, and energy in the pump pulse. From the two equations two unknown matrices $\Delta a_{B C h l}$ and $\Delta a_{C a r}$, which represent BChl $c$ and astaxanthin part of the transient data, could be calculated (Figure 6).

\section{Appendix B. Supplementary material}

Supplementary material is available... 


\section{Figure captions}

Figure 1: Molecular structure of BChl $c$ (a), and astaxanthin (b). Substituents of BChl $c$ at R8 can be ethyl, propyl or isobutyl, at R12 methyl or ethyl. Astaxanthin is drawn as a $\left(3 S, 3^{\prime} S\right)$ isomer.

Figure 2: Absorption spectra of BChl $c$ assemblies with astaxanthin with different astaxanthin-to-BChl $c$ molar ratios, corrected for the light scattering. Absorption spectrum of BChl $c$ dimers (solid line) is shown for comparison. Spectra are normalized at $439 \mathrm{~nm}$ and offset by 0.5 a.u. to ease visualization. The vertical line is located at $715 \mathrm{~nm}$ to facilitate comparison.

Figure 3: Difference spectra between $\mathrm{BChl} c$ assemblies with astaxanthin and $\mathrm{BChl} c$ dimers, showing the contribution of astaxanthin to the absorption spectrum of the assemblies. Spectra are compared with the absorption spectrum of astaxanthin in THF (dotted line).

Figure 4: Absorption (1-T) spectra of BChl $c$ assembly with astaxanthin (solid line) and BChl $c$ dimers (dashed line). The absorption spectra are compared to the fluorescence excitation spectrum of BChl $c$ assembly with astaxanthin (circles). The difference spectrum between both absorption (1-T) spectra (dash dot line), and the difference spectrum between the absorption (1-T) spectrum and the excitation spectrum of BChl $c$ assembly with astaxanthin (dotted line) are also shown.

Figure 5: Transient spectra of BChl $c$-astaxanthin assemblies after excitation at 490nm (a). Transient spectra of BChl $c$ dimers with lecithin after excitation at 490nm (b; negative peak at 590nm is Raman scattering of water). The spectra were smoothed by adjacent averaging.

Figure 6: Transient data of BChl $c$ assemblies with astaxanthin with a an astaxanthin-to-BChl $c$ molar ratio of 0.2:1 after decomposition into a part corresponding to excitation of astaxanthin ( $\mathrm{a}-$ transient spectra, c-decay associated spectra) and BChl $c(\mathrm{~b}$ - transient spectra, $\mathrm{d}$ - decay associated spectra). Arbitrary units for the panels a) and b) are the same and so are they for panels c) and d). The spectra were smoothed by adjacent averaging. 


\section{SUPPLEMENTAL INFORMATION}

Figure S1: Correction of the absorption spectra of BChl c-astaxanthin assemblies for light scattering. Spectra were measured at a position further (solid line) and closer (dotted line) to the detector of the spectrophotometer. The difference between them rescaled to fit the uncorrected spectra above $850 \mathrm{~nm}$ reflects the scattering part of the spectra (dashed line). The corrected spectrum (dash-dot line) was obtained by subtracting the scattering part from the solid line. 

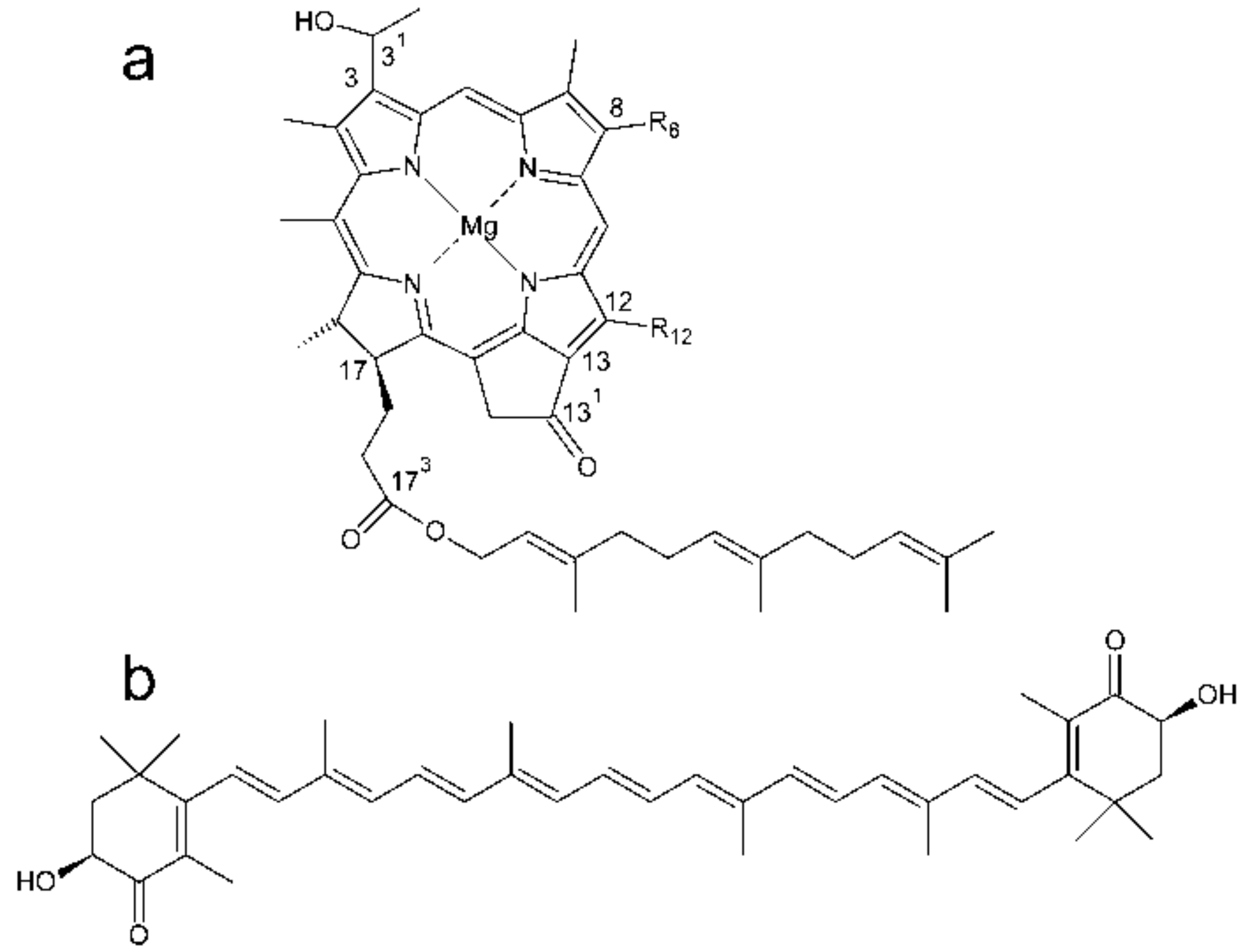


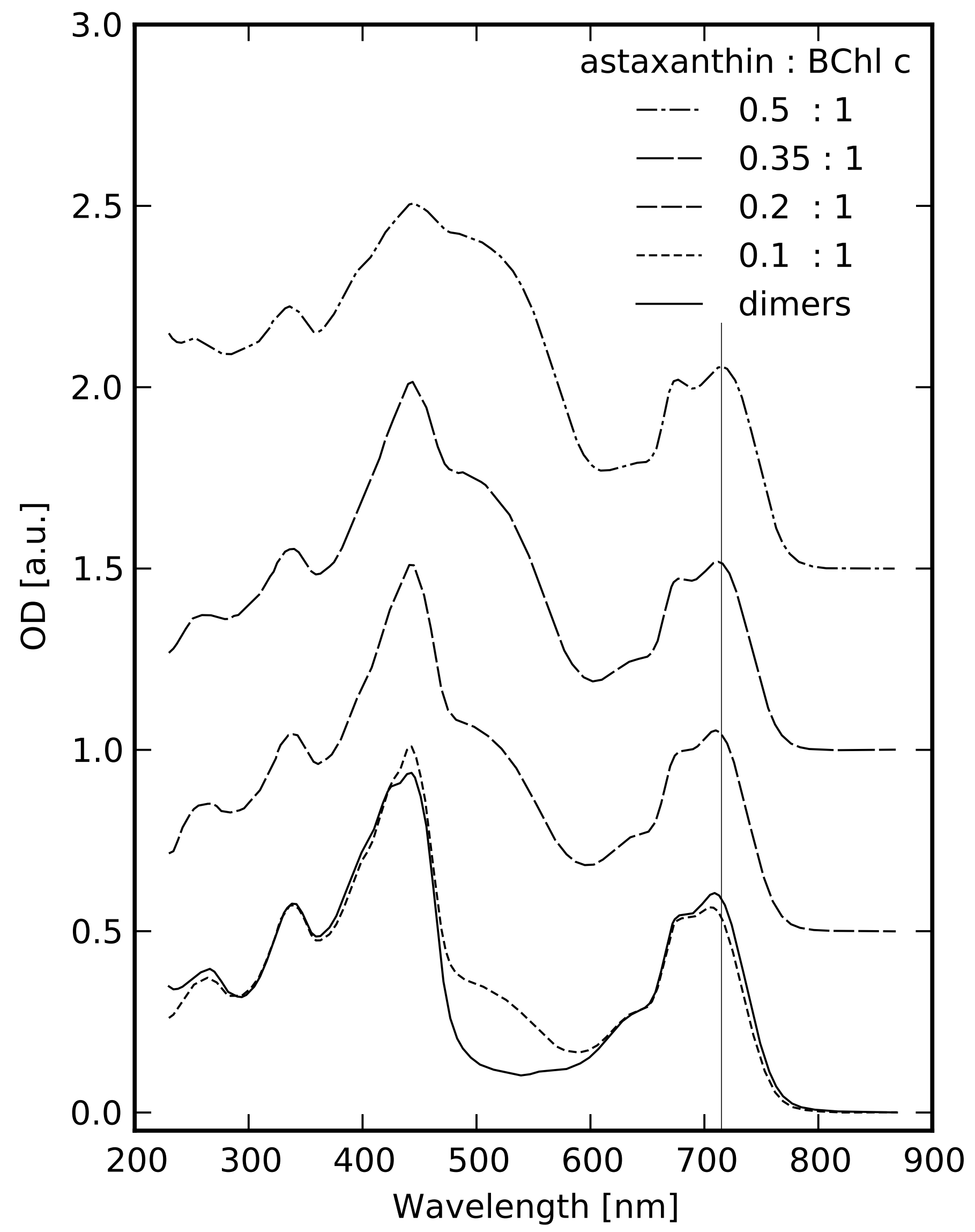




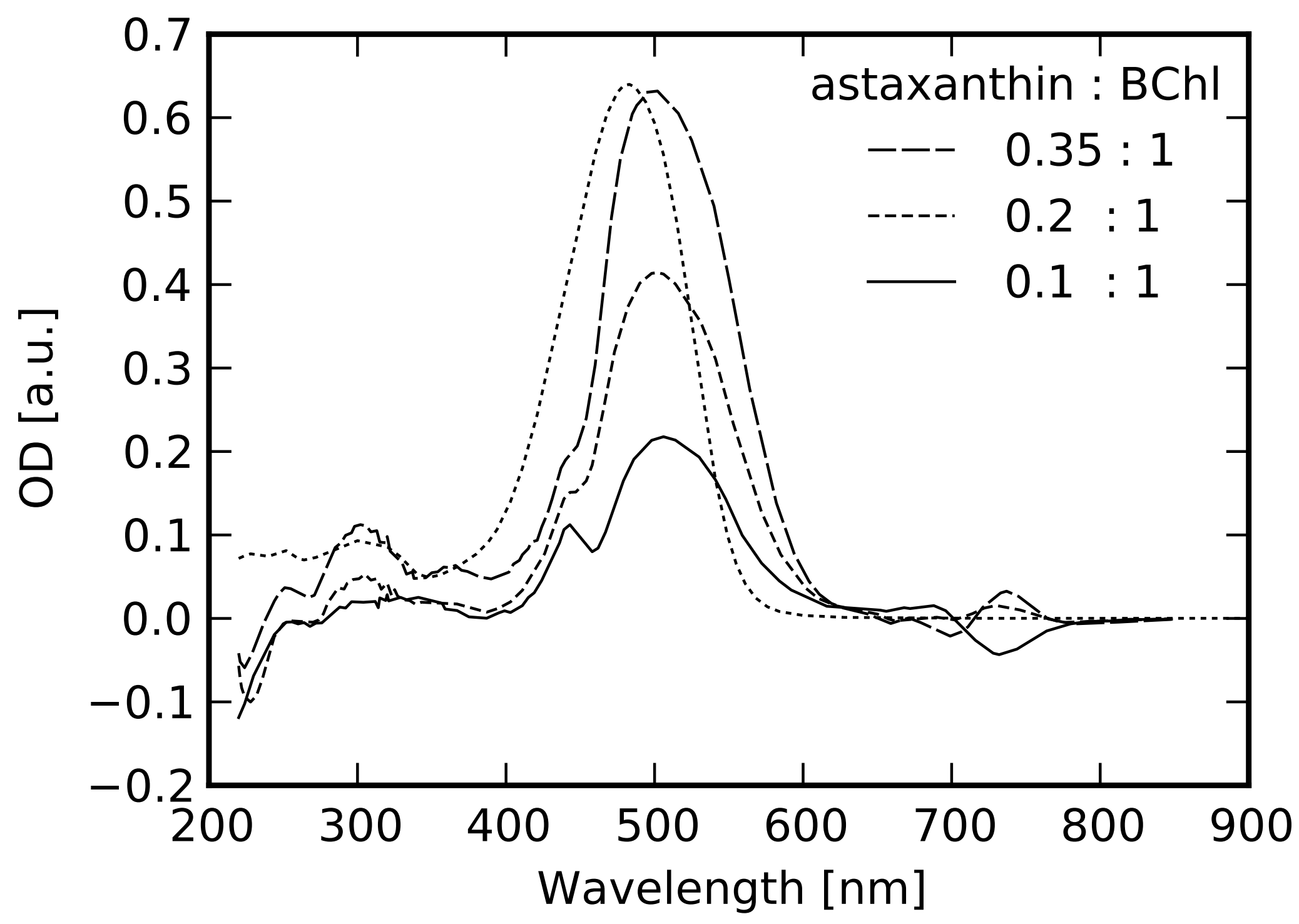




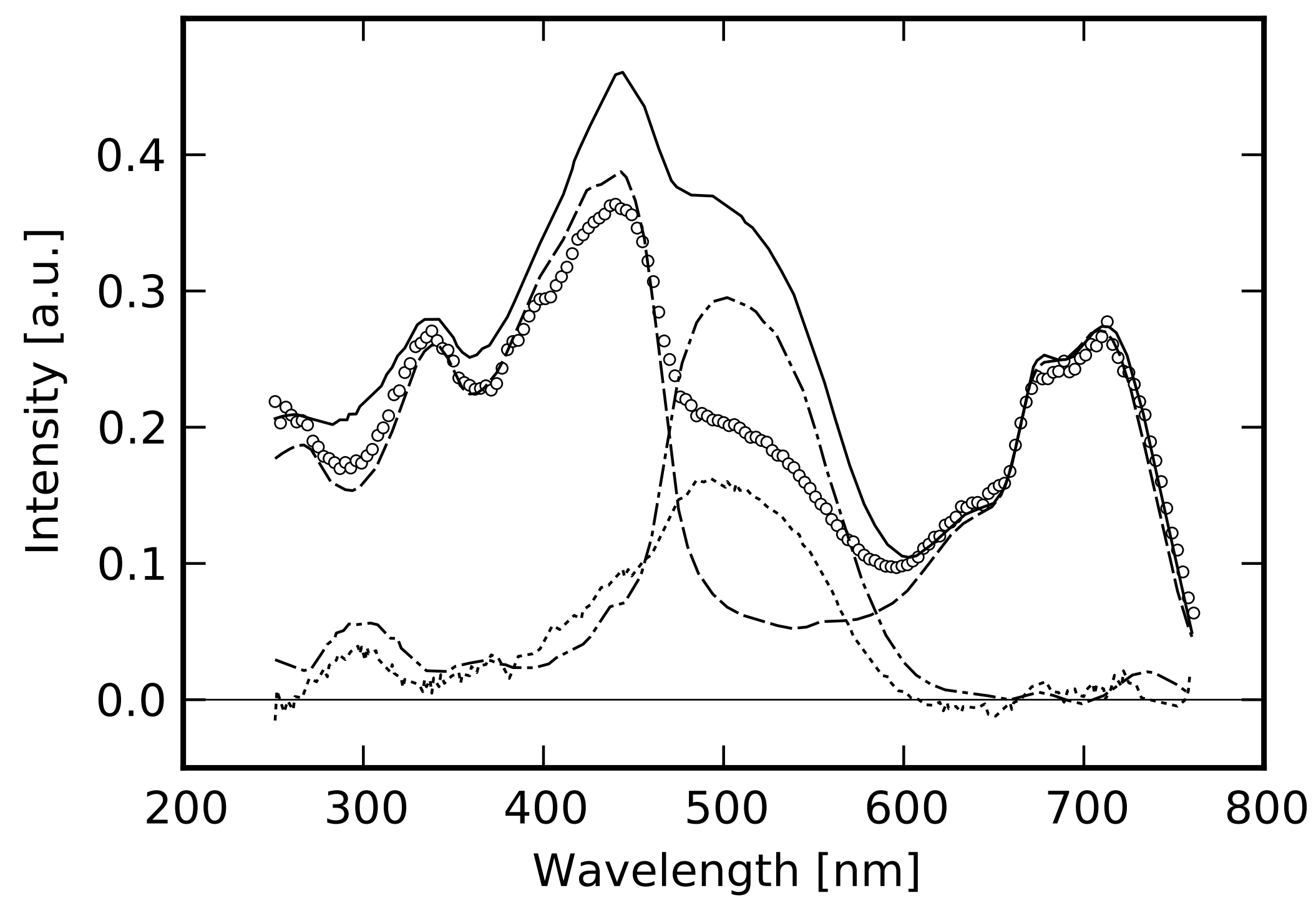



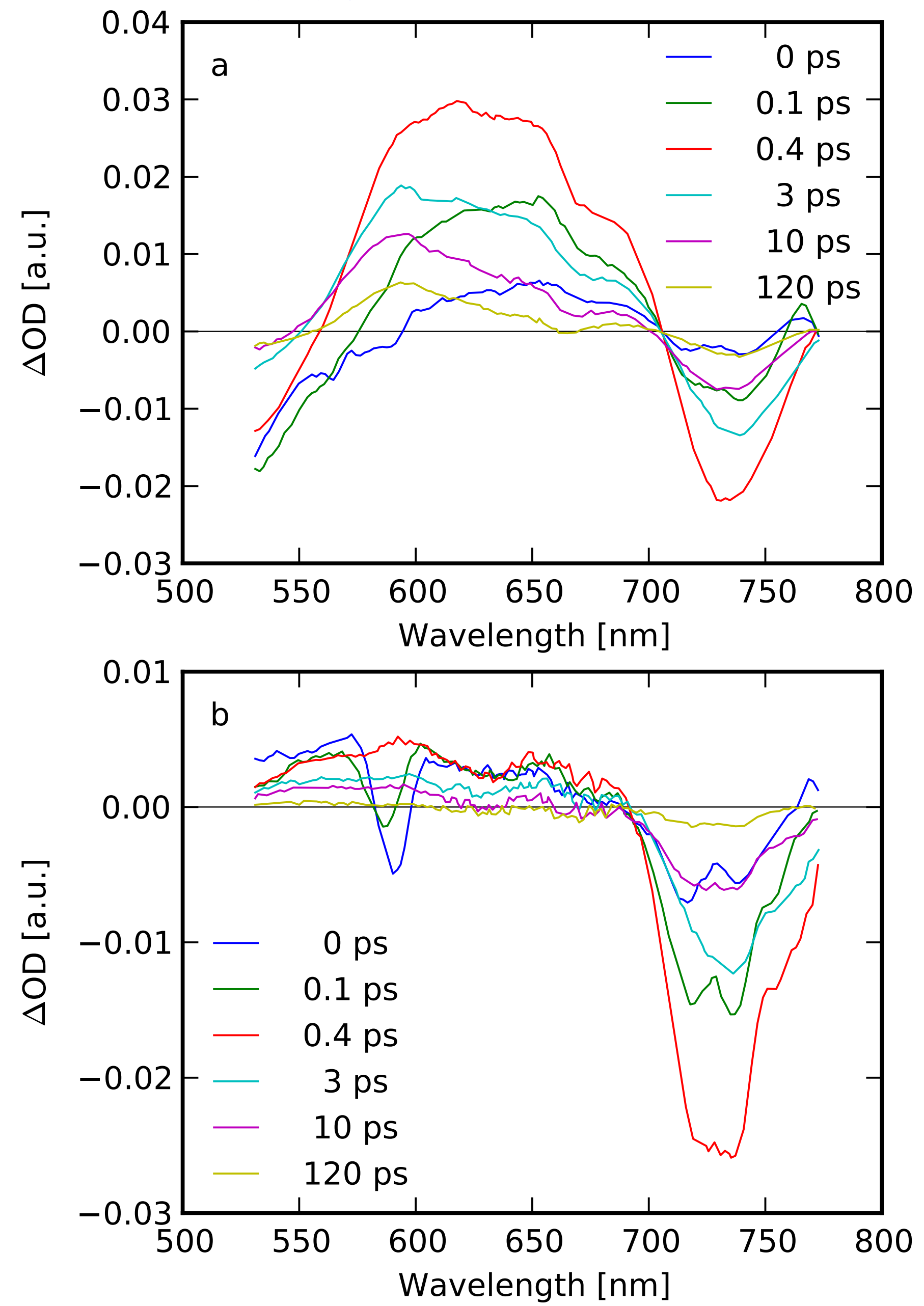

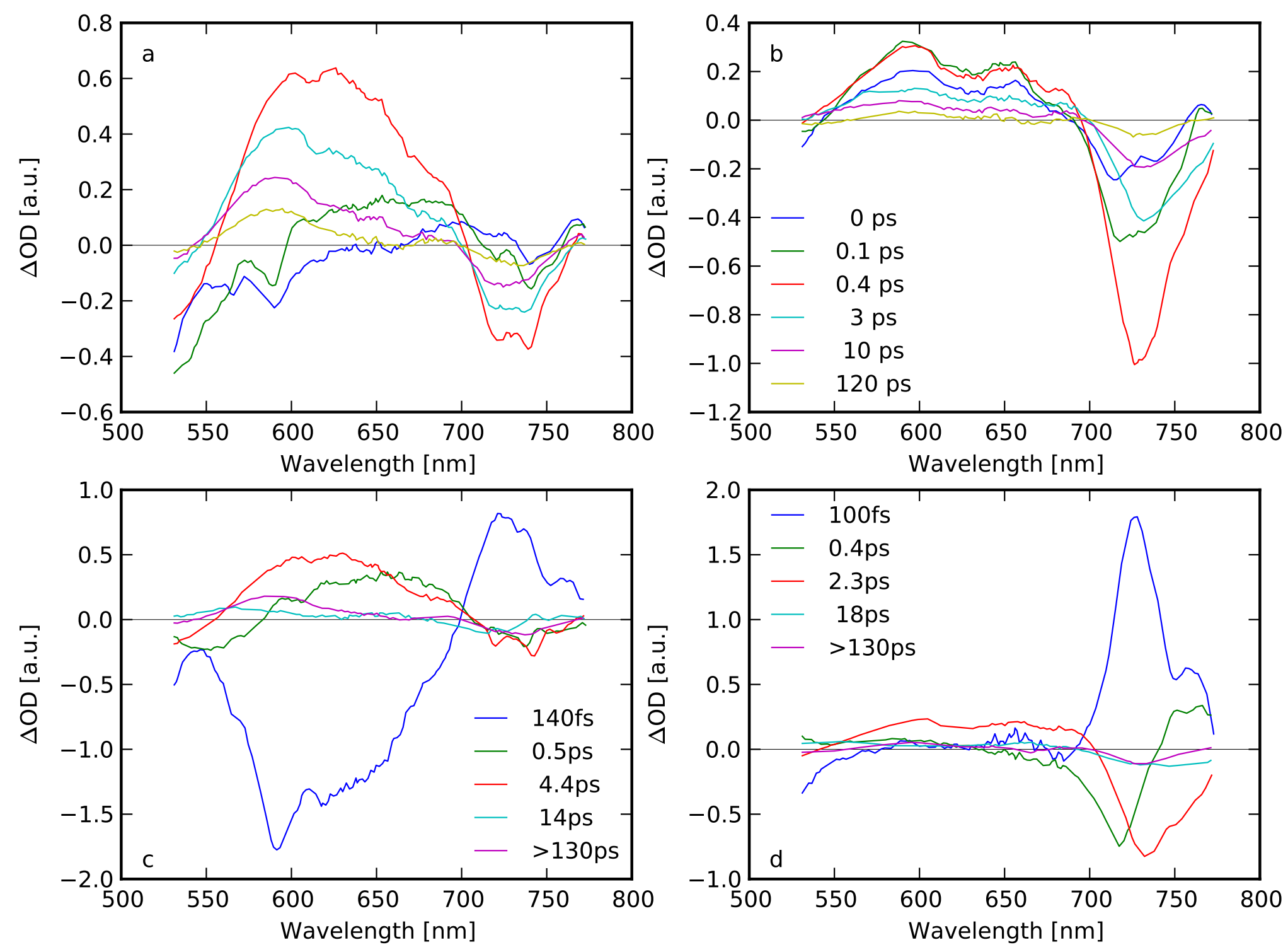


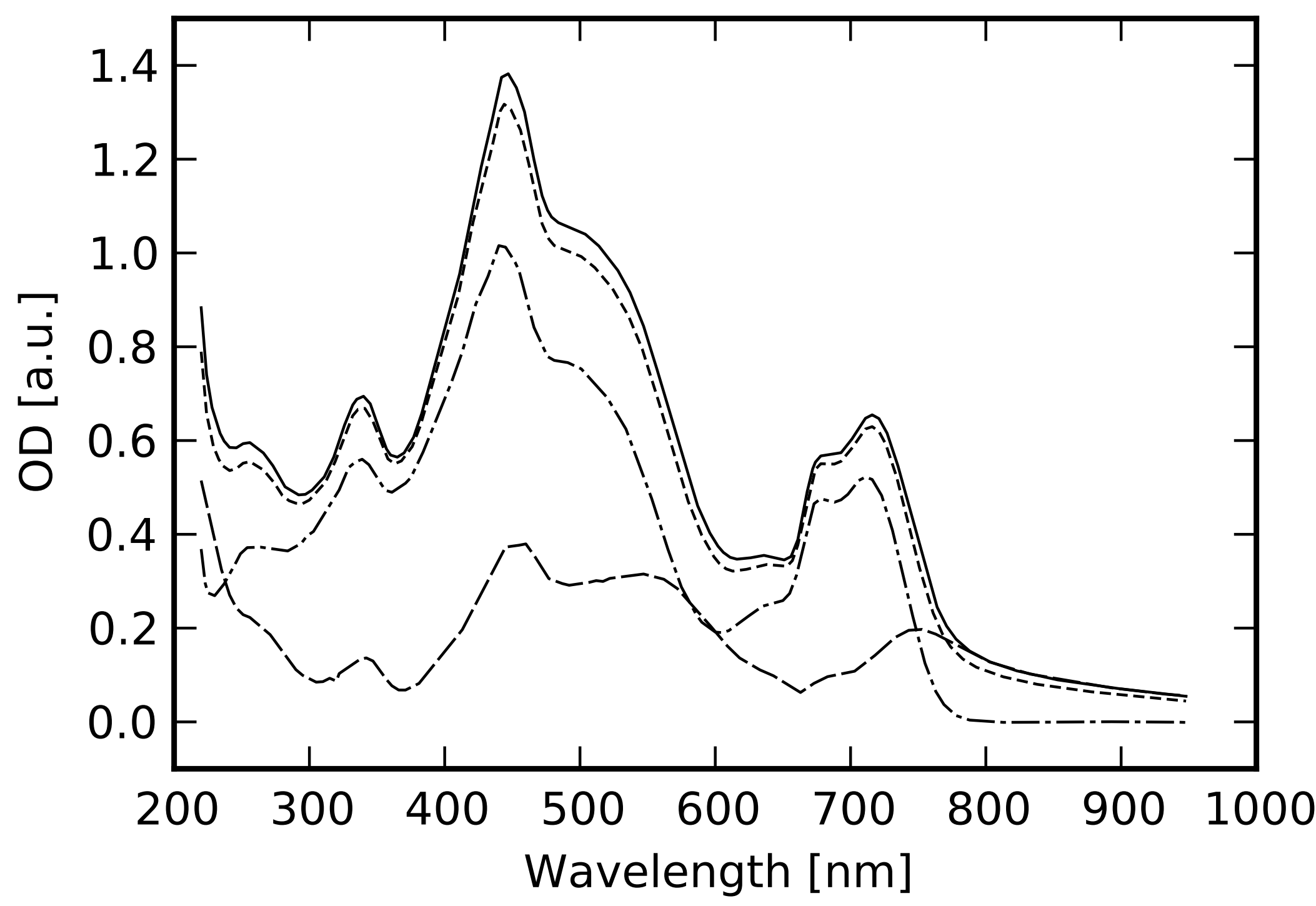

